\title{
Adolescent Varicocele
}

\author{
Serhan Çimen \\ Malatya Education and Research Hospital Urology Clinic, Malatya, Turkey \\ Email: drserhancimen@hotmail.com
}

How to cite this paper: Çimen, S. (2018) Adolescent Varicocele. Open Journal of Urology, 8, 177-183.

https://doi.org/10.4236/oju.2018.86019

Received: April 20, 2018

Accepted: June 16, 2018

Published: June 20, 2018

Copyright $\odot 2018$ by author and Scientific Research Publishing Inc. This work is licensed under the Creative Commons Attribution International License (CC BY 4.0).

http://creativecommons.org/licenses/by/4.0/

\begin{abstract}
Introduction: Adolescent varicocele is still a controversial issue in pediatric urology. In this study, we aimed to evaluate adolescent patients with varicocele, who were operated in our clinic, in the light of literature. Materials and Methods: The data of adolescent patients who underwent varicocelectomy between January 2012 and January 2018 in the Urology Clinic of Malatya Training and Research Hospital were examined retrospectively. The age and admission complaint of the patients, the localization of varicocele, the varicocele grade determined by color Doppler ultrasound (US), the presence of testicular atrophy, the height, weight, body mass index of the patients as well as their relationship with each other were evaluated. Results: The mean age of the patients is 14.74 years ( $10-17$ years). Of the patients, $153(92.2 \%)$ had a left-sided varicocele and $13(7.8 \%)$ had a right-sided varicocele. When admission complaints of the patients were examined, 31 (18.6\%) had scrotal pain, 53 (32.2\%) had scrotal swelling, 21 (12.6\%) had skin bruising, 40 (24\%) had dilated veins recognized by the family, and $21(12.6 \%)$ had more than one complaint. When the relationship between varicocele grade and BMI was examined, 13 (35.1\%) of the 37 patients with a grade 2 varicocele were lean, 23 (62.1\%) were normal weight, and $1(2.8 \%)$ was obese. $12(17.7 \%)$ of the $68 \mathrm{pa}-$ tients with a grade 3 varicocele were lean, $54(79.4 \%)$ were normal weight, and $2(2.9 \%)$ were overweight. $8(13.1 \%)$ of the $61(36.7 \%)$ with a grade 4 varicocele were lean, $46(75.5 \%)$ were normal weight, and 7 (11.4\%) were overweight. Conclusion: Adolescent varicocele is still one of the controversial issues today; the diagnosis should be made with the help of physical examination and radiological tests besides the family's application in boys in this age group in order to prevent possible problems.
\end{abstract}

\section{Keywords}

Adolescent, Varicocele, Body Mass Index

\section{Introduction}

Varicocele is defined as dilatation of the spermatic veins and the plexus pampi- 
niformis which is a scrotal extension of these veins [1]. Although it is rarely seen in the prepubertal period, it increases during puberty. It peaks around the age of thirteen. This rate increases up to $15 \%$ between ten and nineteen years of age. This rate is similar to the rates in adults [2] [3]. Several rates on the prevalence of adolescent varicocele have been reported in the literature. These rates have ranged from $9 \%$ to $42.8 \%$ [4] [5]. Adolescent varicocele is still a controversial issue in pediatric urology [6]. Children and adolescents with varicocele may experience fertility problems in the future. Therefore, it is still being discussed that they need to undergo surgical treatment and can benefit from this treatment [7]. In this study, we aimed to evaluate adolescent patients with varicocele, who were operated in our clinic, in the light of literature.

\section{Materials and Methods}

The data of adolescent patients who underwent varicocelectomy between January 2012 and January 2018 in the Urology Clinic of Malatya Training and Research Hospital were examined retrospectively. The age and admission complaint of the patients, the localization of varicocele, the varicocele grade determined by color Doppler ultrasound (US), the presence of testicular atrophy, the height, weight, body mass index of the patients as well as their relationship with each other were evaluated.

\section{Results}

The mean age of the patients is 14.74 years (10 - 17 years). Of the patients, 153 (92.2\%) had a left-sided varicocele and $13(7.8 \%)$ had a right-sided varicocele. All patients underwent preoperative color Doppler US. According to examination with color Doppler US, 37 (22.4\%) had a grade 2 varicocele, 68 (40.9\%) had a grade 3 varicocele, and 61 (36.7\%) had a grade 4 varicocele. 18 (10.8\%) had testicular atrophy. When admission complaints of the patients were examined, 31 (18.6\%) had scrotal pain, 53 (32.2\%) had scrotal swelling, 21 (12.6\%) had skin bruising, 40 (24\%) had dilated veins recognized by the family, and 21 (12.6\%) had more than one complaint. While 142 patients had a negative family history of varicocele, 24 patients had a positive family history of varicocele (Table 1). The mean body weight of the patients was $47.2 \mathrm{~kg}(23-68 \mathrm{~kg})$, and the mean height of the patients was $151 \mathrm{~cm}(124-171 \mathrm{~cm})$. According to body mass index (BMI), 33 patients were lean, 123 patients were normal weight, 9 patients were overweight, and 1 patient was obese. When the relationship between varicocele grade and BMI was examined, 13 (35.1\%) of the 37 patients with a grade 2 varicocele were lean, $23(62.1 \%)$ were normal weight, and 1 (2.8\%) was obese. 12 (17.7\%) of the 68 patients with a grade 3 varicocele were lean, $54(79.4 \%)$ were normal weight, and $2(2.9 \%)$ were overweight. $8(13.1 \%)$ of the $61(36.7 \%)$ with a grade 4 varicocele were lean, $46(75.5 \%)$ were normal weight, and $7(11.4 \%)$ were overweight (Table 2). When the relationship between varicocele grade and admission complaint was examined, $15(40.5 \%)$ of the 37 patients with a grade 2 
Table 1. Admission complaint.

\begin{tabular}{cc}
\hline Scrotal Pain & $31(18.7 \%)$ \\
Scrotal Swelling & $53(31.9 \%)$ \\
Skin Bruising & $21(12.7 \%)$ \\
Recognition of Dilated Veins & $40(24 \%)$ \\
More than one Complaint & $21(12.7 \%)$ \\
Total & 166 \\
\hline
\end{tabular}

Table 2. Relationship between varicocele grade and BMI.

\begin{tabular}{cccc}
\hline & GRADE 2 & GRADE 3 & GRADE 4 \\
\hline Lean & $13(35.1 \%)$ & $12(17.7 \%)$ & $8(13.1 \%)$ \\
Normal & $23(62.1 \%)$ & $54(79.4 \%)$ & $46(75.5 \%)$ \\
Overweight & - & $2(2.9 \%)$ & $7(11.4 \%)$ \\
Obese & $1(2.8 \%)$ & - & - \\
Total & $37(100 \%)$ & $68(100 \%)$ & $61(100 \%)$ \\
\hline
\end{tabular}

varicocele had scrotal pain, $16(43.2 \%)$ had scrotal swelling, and 6 (16.3\%) had skin bruising. $16(23.5 \%)$ of the 68 patients with a grade 3 varicocele had scrotal pain, 32 (47\%) had scrotal swelling, 10 (14.7\%) had had skin bruising, 7 (10.2\%) had dilated veins recognized by the family, and $3(4.6 \%)$ had more than one complaint. $5(8.1 \%)$ of the $61(36.7 \%)$ with a grade 4 varicocele had scrotal swelling, $5(8.1 \%)$ had skin bruising, 33 (54\%) had dilated veins recognized by the family, and 18 (29.8\%) had more than one complaint (Table 3).

\section{Discussion}

Varicocele is defined as dilatation of the spermatic veins and the plexus pampiniformis which is a scrotal extension of these veins. The right internal spermatic vein is approximately $10 \mathrm{~cm}$ shorter than the left internal spermatic vein and drains directly into the vena cava inferior. Therefore, it creates a hydrostatic pressure difference and sets the ground for the formation of varicoceles. Varicocele is frequently observed on the left side when the literature is examined. It is rarely seen on the right side or both sides [8] [9]. In our study, the majority of patients had a left-sided varicocele in accordance with the literature.

In recent years, scrotal color Doppler ultrasound is frequently used to determine the degree of varicocele and venous reflux [10]. Our patients underwent color Doppler ultrasound. The majority of these patients had a grade 3 varicocele. It is important to assess the testicular volume in patients with high-grade varicocele. Ultrasound is used to determine this volume. In ultrasonographic measurement, the length, width and height of the testis are measured in $\mathrm{mm}$, and the testicular volume is calculated by the Lambert formula (TV $=0.71 \times$ width $\times$ length $\times$ height) [11]. It has been shown that the Lambert formula gives 
Table 3. Relationship between varicocele grade and admission complaint.

\begin{tabular}{cccc}
\hline & GRADE 2 & GRADE 3 & GRADE 4 \\
\hline Scrotal Pain & $15(40.5 \%)$ & $16(23.5 \%)$ & - \\
Scrotal Swelling & $16(43.2 \%)$ & $32(47 \%)$ & $5(8.1 \%)$ \\
Skin Bruising & $6(16.3 \%)$ & $10(14.7 \%)$ & $5(8.1 \%)$ \\
Recognition of Dilated Veins & - & $7(10.2 \%)$ & $33(54 \%)$ \\
More than one Complaint & - & $3(4.6 \%)$ & $18(29.8 \%)$ \\
Total & 37 & 68 & 61 \\
\hline
\end{tabular}

more accurate results when compared to other volume measurements [12]. Testicular volume differential (TVD) is calculated by the following formula: volume of unaffected testis - volume of affected testis/total testicular volume $\times 100(\%)$. Testicular atrophy index (TAI) is calculated by the following formula: volume of unaffected testis - volume of affected testis/volume of unaffected testis $\times 100(\%)$ [13] [14]. The presence or absence of testicular atrophy is calculated in this way. Testicular hypotrophy is defined as testicular volume below $2 \mathrm{ml}$ by ultrasound and more than $20 \%$ difference in testicular volume relative to the contralateral testis [15]. Testicular hypotrophy is among the indications for surgery [16]. In our study, approximately $1 / 10$ of the adolescent patients who underwent surgery due to varicocele had testicular atrophy.

Although varicocele in childhood and adolescence is typically asymptomatic, few patients have symptoms and complaints. They seldom present with pain and are sometimes detected due to dilated veins and skin bruising recognized by the family. Sometimes, they are detected when parents recognize the difference between the two testes and thereby bring their children to the clinical examination [10] [17] [18] [19]. In our study, the most common admission complaint of the patients was scrotal swelling. This was followed by dilated veins recognized by the family and local skin bruising.

The incidence of varicocele in the patients whose first-degree relatives (such as a father or brother) had varicocele was found to be 3 - 4 times higher than the normal population [20] [21]. In our study, 24 (14.4\%) of the patients had a positive family history of varicocele.

The relationship between adolescent varicocele, weight and BMI is still unclear [22]. Although some studies have revealed a positive correlation between the incidence of adolescent varicoceles and weight gain, it has been shown to be inversely proportional to reduced body mass index [23]-[28]. When the literature is examined, various studies have shown that the incidence of varicocele is decreased in overweight and obese men [29] [30] [31] [32]. In a large-scale study by Liu et al., it was shown that varicocele grade was decreased with reduced body mass index [22] [28]. In our study, while the patients with a low BMI had a low-grade varicocele, the patients with a high BMI had a high-grade varicocele.

When the literature is examined, there are a limited number of studies assessing the relationship between varicocele grade and BMI. These studies have been 
conducted on adults. Fazeli et al. found that the patients with a low BMI had a high-grade varicocele [33]. In our study, it was seen that varicocele grade increased as BMI increased.

Varicocele causes progressive damage to the testis through various mechanisms and can lead to infertility. Although adolescent varicocele is still one of the controversial issues today, the diagnosis should be made with the help of physical examination and radiological tests besides the family's application in boys in this age group in order to prevent possible problems. We think that a large number of studies are needed in order to clarify the relationship of adolescent varicocele with demographic characteristics.

\section{References}

[1] Robinson, S.P., Hampton, L.J. and Koo, H.P. (2010) Treatment Strategy for the Adolescent Varicocele. Urologic Clinics of North America, 37, 269-278. https://doi.org/10.1016/j.ucl.2010.03.011

[2] Oster, J. (1971) Varicocele in Children and Adolescents. An Investigation of the Incidence among Danish School Children. Scandinavian Journal of Urology and Nephrology, 5, 27-32. https://doi.org/10.3109/00365597109133569

[3] Akbay, E., Cayan, S., Doruk, E., Duce, M.N. and Bozlu, M. (2000) The Prevalence of Varicocele and Varicocele-Related Testicular Atrophy in Turkish Children and Adolescents. BJU International, 86, 490-493. https://doi.org/10.1046/j.1464-410X.2000.00735.x

[4] Berger, O.G. (1980) Varicocele in Adolescence. Clinical Pediatrics (Phila), 19, 810-811. https://doi.org/10.1177/000992288001901205

[5] Pfeiffer, D., Berger, J., Schoop, C. and Tauber, R. (2006) A Doppler-Based Study on the Prevalence of Varicocele in German Children and Adolescents. Andrologia, 38, 13-19. https://doi.org/10.1111/j.1439-0272.2006.00680.x

[6] Haddad, N.G., Houk, C.P. and Lee, P.A. (2014) Varicocele: A Dilemma in Adolescent Males. Pediatric Endocrinology Reviews, 11, 274-283.

[7] Kass, E.J. and Belman, A.B. (1987) Reversal of Testicular Growth Failure by Varicocele Ligation. Journal of Urology, 137, 475-476. https://doi.org/10.1016/S0022-5347(17)44072-9

[8] Höllwarth, M.E. (2006) Varicocele. In: Puri, P. and Höllwarth, M., Eds., Pediatric Surgery, Springer-Verlag Berlin Heidelberg, 569. https://doi.org/10.1007/3-540-30258-1_54

[9] Hutson, J.M. (2006) Undescended Testis, Torsion and Varicocele. In: O’Neill, J.A., Grosfeld, J.L., James, A., Fonkalsrud, E.W. and Coran, A.G., Eds., Pediatric Surgery, Mosby, Philadelphia, 1193.

[10] Uğuz, S. and Irkılataa, H.C. (2015) Adolescent Varicocele. Turkiye Klinikleri Journal of Urology Special Topics, 8, 86-92.

[11] Lambert, B. (1951) The Frequency of Mumps and of Mumps Orchitis and the Consequences for Sexuality and Fertility. Acta Genetica Et Statistica Medica, 2, 1-166.

[12] Hsieh, M.L., Huang, S.T., Huang, H.C., Chen, Y. and Hsu, Y.C. (2009) The Reliability of Ultrasonographic Measurements for Testicular Volume Assessment: Comparison of Three Common Formulas with True Testicular Volume. Asian Journal of Andrology, 11, 261-265. https://doi.org/10.1038/aja.2008.48 
[13] Niedzielski, J., Paduch, D. and Raczynski, P. (1997) Assessment of Adolescent Varicocele. Pediatric Surgery International, 12, 410-413. https://doi.org/10.1007/BF01076952

[14] Christman, M.S., Zderic, S.A. and Kolon, T.F. (2014) Comparison of Testicular Volume Differential Calculations in Adolescents with Varicoceles. Journal of Pediatric Urology, 10, 396-398. https://doi.org/10.1016/j.jpurol.2013.12.007

[15] Diamond, D.A., Zurakowski, D., Bauer, S.B., et al. (2007) Relationship of Varicocele Grade and Testicular Hypotrophy to Semen Parameters in Adolescents. Journal of Urology, 178, 1584-1588. https://doi.org/10.1016/j.juro.2007.03.169

[16] Ünal, D., Erbağc1, A., Güneş, A., Ersay, A., Semerciöz, A., Satar, N. and Sarıca, K. (2002) Peripubertal Varinations of Testicular Size in Adolescent Varicocele: Gapug Series. Türk Üroloji Dergisi, 28, 161-165.

[17] Özkan, S., Özbek, E., Gürpınar, T., Sarıüce, O., Güneş, A. and Özsan, Ö. (1996) Prevalence of Varicocele in Adolescence and Use of Doppler USG. Turgut Özal Tip Merkezi Dergisi, 3, 210-212.

[18] Öztürk, E. and Soygür, T. (2013) Adölesan varikosel. Androloji Bülteni, 53, 103-105.

[19] Aksoy, Y., Ziypak, T. and Adanur, Ş. (2012) Turkiye Klinikleri. Journal of Urology, 5, 61-66.

[20] Raman, J.D., Walmsley, K. and Goldstein, M. (2005) Inheritance of Varicoceles. Urology, 65, 1186-1189. https://doi.org/10.1016/j.urology.2004.12.057

[21] Gökçe, A., Davarci, M., Yalçinkaya, F.R., Güven, E.O., Kaya, Y.S., Helvaci, M.R., et al. (2010) Hereditary Behavior of Varicocele. Journal of Andrology, 31, 288-290. https://doi.org/10.2164/jandrol.109.008698

[22] Liu, J., Zhang, S., Liu, M., Wang, Q., Shen, H., Zhang, Y. and Yan, D. (2017) Prevalence of Varicocoele and Its Association with Body Mass Index among 39,559 Rural Men in Eastern China: A Population-Based Crosssectional Study. Andrology, 5, 562-567. https://doi.org/10.1111/andr.12345

[23] Delaney, D.P., Carr, M.C., Kolon, T.F., Snyder, H.M. and Zderic, S.A. (2004) The Physical Characteristics of Young Males with Varicocele. BJU International, 94, 624-626. https://doi.org/10.1111/j.1464-410X.2004.05013.x

[24] Shin, J.I. and Lee, J.S. (2007) Changes in Body Mass Index and Prevalence of Varicoceles during Adolescence. Urologia Internationalis, 78, 178. https://doi.org/10.1159/000098079

[25] Prabakaran, S., Kumanov, P., Tomova, A., Hubaveshki, S. and Agarwal, A. (2006) Adolescent Varicocele: Association with Somatometric Parameters. Urologia Internationalis, 77, 114-117. https://doi.org/10.1159/000093902

[26] Nielsen, M.E., Zderic, S., Freedland, S.J. and Jarow, J.P. (2006) Insight on Pathogenesis of Varicoceles: Relationship of Varicocele and Body Mass Index. Urology, 68, 392-396. https://doi.org/10.1016/j.urology.2006.02.005

[27] Kumanov, P., Robeva, R.N. and Tomova, A. (2008) Adolescent Varicocele: Who Is at Risk? Pediatrics, 121, e53-e57. https://doi.org/10.1542/peds.2007-0340

[28] May, M., Taymoorian, K., Beutner, S., Helke, C., Braun, K.P., Lein, M., et al. (2006) Body Size and Weight as Predisposing Factors in Varicocele. Scandinavian Journal of Urology and Nephrology, 40, 45-48. https://doi.org/10.1080/00365590500407795

[29] Rais, A., Zarka, S., Derazne, E., Tzur, D., Calderon-Margalit, R., Davidovitch, N., Afek, A., Carel, R. and Levine, H. (2013) Varicocoele among 1300000 Israeli Adolescent Males: Time Trends and Association with Body Mass Index. Andrology, 1, 
663-669. https://doi.org/10.1111/j.2047-2927.2013.00113.x

[30] Gokce, A., Demirtas, A., Ozturk, A., Sahin, N. and Ekmekcioglu, O. (2013) Association of Left Varicocoele with Height, Body Mass Index and Sperm Counts in Infertile Men. Andrology, 1, 116-119. https://doi.org/10.1111/j.2047-2927.2012.00014.x

[31] Doğantekin, E., Görgel, S.N., Şahin, E. and Girgin, C. (2014) Relationship between Varicocele and Anthropometric Indices in Infertile Population. Dicle Medical Journal, 41, 59-63. https://doi.org/10.5798/diclemedj.0921.2014.01.0373

[32] Hassanzadeh, K., Yavari-Kia, P., Soleymanpour, H., Ebrahimpour, N. and Alikhan, H. (2011) Effect of Body Mass Index and Prevalence of Varicocele. Pakistan Journal of Biological Sciences, 14, 806-875. https://doi.org/10.3923/pjbs.2011.869.875

[33] Fazeli, F., Shahraki, M., Bazzaz, M.M. and Fazeli, K. (2015) Association between Body Mass Index and Frequency and Grade of Varicocele in Southeast Iran. Journal of Medicine and Life, 8, 62-65. 